\title{
Autonomy and Citizenship Effects of the Gap Year Experience
}

\author{
Ana Mouraz, Ligia Araujo \\ Faculty of Psychology and Sciences of Education, Porto University, Portugal
}

\begin{abstract}
In this paper we try to understand to what extent the experience of the gap year challenges and develop the autonomy of these young people, or gappers. The study explores changes the experience provides ex-gappers, as the youths are aware of them and as changes are visible for others. This is important as autonomy is a desire and aim of any educational system and a requirement for society integration and selfachievement. This is an occasional study conducted with seven people who came to university after a gap year experience. Interviews were made with ex-gappers, their relatives or close friends and a responsible person from a funding institution. Gap year experience changes ex-gappers' beliefs and practices broadly related to personal autonomy. Their relatives and the funding person witnessed these changes. Results regarding citizenship and social commitment after the experience show that those who travel alone evidence more concerns regarding social issues.
\end{abstract}

Keywords: Gap year, autonomy, citizenship, personal and social changes.

\section{INTRODUCTION}

Personal autonomy is of the most importance in educational paths, and not only as a goal of formal education or as a common trend of national curricula worldwide. It also is the key issue of citizenship in a complex and globalized world such as ours (Sinnema \& Aitken, 2014). The literature stresses the impact of autonomy development, or the lack of it, as it affects the future of personal lives (Ribeiro, 2014). Because it also affects the future of a country in a socio-economic and cultural perspective, it is of growing importance as an educational goal. The broad landscape within which this statement is important at an institutional level is that it usually is related with quality descriptors of education systems as it could mean that institutions are not doing enough to perform their mission - to fully promote students' autonomy (Duarte, Leite, \& Mouraz, 2015). As noted, autonomy is a desire and aim of any educational system (Biesta, 2009) and a requirement for society integration. Therefore, it is important to define personal autonomy.

In the steps of enlightening ideas, autonomy is the ability to think and act by oneself (Kant, 1988), finding one's own law by thinking properly and acting accordingly. Within such close connections between reason and action it is possible to question how autonomy is supposed to be developed by anyone during his or her own process of being (this is equal to the process of learning to be oneself). Educational systems talk about this regarding the teaching and learning interaction, but it could be understood as Brockett and Hiemstra (1991) did by attributing the teaching and learning transaction as a main responsibility of the learner and by defining it as a 'process in which a learner assumes primary responsibility for planning, implementing, and evaluating the learning process' (p. 24).

This changed paradigm that stresses the learning process of being oneself as a major responsibility of learner is the frame for understanding the gap year. Therefore, some experiences lived by youths outside school walls develop personal autonomy and civic commitment in broad and deep ways (Coetzee \& Bester, 2009; Crawford \& Cribb, 2012; O'Shea, 2011). That is the case of gap year experience.

\subsection{Gap Year Concept and Relation with Personal Autonomy}

The gap year is a year out of the academic path, usually experienced by young people after completing high school and before enrolling in university. It usually is profited to travel, to contact with other cultural contexts, namely underdeveloped nations, and to do some volunteer work in such contexts (Coetzee \& Bester, 2009; Crawford \& Cribb, 2012). It is different from just a traveling and 
touristic experience because of its duration and travel conditions (Snee, 2010; Spenader, 2011). Also it is different from an academic mobility, as the Erasmus scholarship, as it is not framed by any institutional protocol and has no effect on academic curriculum. In such a perspective, the gap year experience requires more autonomous skills and risk awareness than other similar situations (Araújo \& Mouraz, 2015b; Head, 2007).

Traveling to improve personal skills, to grow up and to experience the transition to adulthood in a more radical way seems to be the main motivation reported in a set of studies conducted on the subject regarding the context of several western countries (O'Shea, 2011; Snee, 2010). Another connection with autonomy is the time to think about the future and decisions. Martin (2010) concluded that taking a gap year could be profitable in solving motivation problems and post-school uncertainty, and it is connected with having the necessary time and distance to make decisions for the future.

Mary (2014) said that 'Today's young people experience transition in an inconsistent set of economic and social conditions. In particular, socioeconomic fluctuations compromise their integration into the labour market and their possibilities of achieving financial autonomy' (p.416). As experiences enable gappers to make contact with very diverse realities and face real challenges to go further with their purpose, it is possible to conclude that the gap year experience is a kind of essay or rehearsal of times they shall face (Nico, 2014).

\subsection{Gap Year Studies and Relation with Citizenship and Civic Intervention}

The second trend that can be explored concerning gap year changes relates the traveling experience with citizenship and improvement in social commitment. Traveling allows a deep contact with some realities that young people previously only might have seen only via television or social media. For the large majority who come from structured and supporting middle class families, the experience is a challenge to their values and lifestyles.

Concepts like freedom, tolerance, democracy, basic rights or access to education never before were challenged or faced as discussable. Araújo and Mouraz (2015a) stated that such concepts are closely related in the western countries context, and the gap year phenomenon is one that moves young people from developed countries to underdeveloped ones, not in the opposite direction. Nevertheless, it is possible to discuss such issues in a non-colonialist perspective (Johan, 2009). Therefore gappers must decontextualize these concepts in different contexts from their own. Sometimes performing volunteer work during the gap year experience is a kind of obligation that gappers have to develop (Simpson, 2004); these particular experiences are of the utmost importance to operationalize the aforementioned concepts.

Furthermore, the gap year experience seems to be relevant in an ethical point of view as it enables people inevitably to reflect on otherness and social justice (Johan, 2009; Raymond, \& Hall, 2008). Also, the literature stresses the effects of such involvement in volunteer work on further initiatives and social activities that ex-gappers are available to perform. O'Shea (2011) related that 'Back in university, returned volunteers often recalled becoming more involved in their field of study (often relating the material to their gap year experience) and related extra-curricular activities' (p. 571).

Jones (2004) remarked that effects related with the gap year experience seem to point to a connection between volunteer work and personal and social skills development. In fact, Jones reported results as: '(1) improved educational performance; (2) formation and development of educational and career choices; (3) reduced likelihood of future "dropout" from education, training or employment; (4) improved "employability" and career opportunities; (5) non-academic skills and qualifications development; (6) social capital and civic engagement; (7) life skills and social values development' (p. 58).

This idea also is stressed by O'Shea (2011), who went further when he concluded that 'They choose to take an international volunteering gap year, spending a year in a developing community teaching or doing social or community work (...) may help universities to form not just good future employees, but citizens of character' (p. 577).

In this paper we will try to understand to what extent experience of the gap year challenges and develops the autonomy of young people. Thus, the study explores changes that the experience provided ex-gappers, as they are aware of them, and as changes are visible for others. Specific 
objectives are (a) to identify and characterize the changes that gap year experience had on ex-gappers' beliefs and practices, broadly related to autonomy and (b) to relate such changes with citizenship and social commitment, namely within higher education contexts to which the ex-gappers returned.

\section{METHODOLOGY}

This is an occasional study focused on the possible changes occurred in young people who took a gap year and then entered college. This study was done to better understand the concept of the gap year in Portugal and its possible implications for education, especially in the higher education system.

Data were collected through interviews of former gappers who are now (or were at the moment of the interview) in college. These contacts were initiated by people from two organizations that support the gap year experience in Portugal: the Associação Gap Year Portugal and Fundação Lapa do Lobo. Therefore this is a case of occasional selection. Other participants were family members or close friends identified by each of the young people, as well as an interview with a member of a Portuguese foundation that helped fund several gap year experiences.

Seven former gappers were interviewed. Six of them indicated a family member or close friend who could characterize their gap year experience; one gapper didn't indicate a name in useful time. Only five witness interviews could be used, however, because sound interference on the recording made one interview impossible to understand. Finally, a representative of the Fundação Lapa do Lopo was interviewed.

In total, 13 interviews were conducted, following a semi-structured logic. These interviews were carried out between May and June 2015. Due to geographical distance and the impossibility of travelling to meet the participants, the interviews were made using Skype. During the moment of data collection all ethical conditions of anonymity and data protection were assured.

Transcripts were made of the interviews, and transcripts were analysed using Nvivo version 10 software. Transcriptions were 'ideational', meaning that transcriptions were faithful to interviewees' thoughts (Bogdan \& Biklen, 1994).

As stated previously, autonomy can be defined as the personal ability to learn by oneself. For the purpose of present study autonomy is defined following the model operationalized by Brockett and Hiemstra (1991) which includes four main dimensions: self-efficacy, control, initiative and motivation. These were the main structure under which interviews were made and analysed.

Interviews with gappers were focused in four main axes: general motivation to do the travel experience, main features that frame travel choices and aspects that occurred during travel, difficulties faced during the experience, and effects on personal lives and following academic paths. Guidelines for the interviews with witnesses focused on the main motivations for traveling (as the witnesses were told or understood) and the main changes they saw in gappers' way of being. The financier's interview followed two main axes: characteristics of the young people who made the gap year and the changes occurred in them derived from their experience.

To analyse these data, the three different sources of data were triangulated as shown in Figure 1. After data were triangulated, they were analysed sequentially according to this order: inventory of the changes, characterization of the identified changes and examination of their dimension impact.

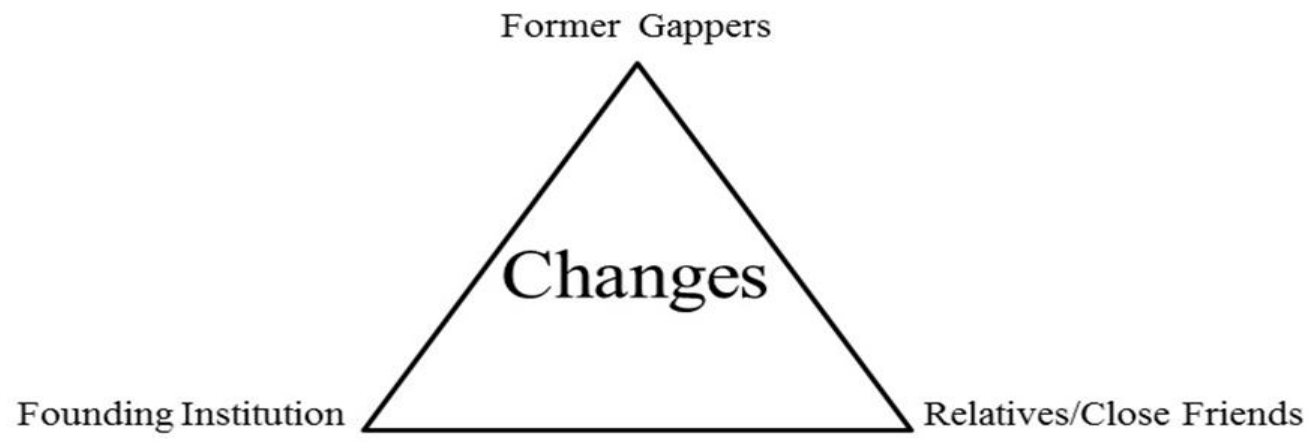

Figure1. Methodological framework 


\section{RESUlTS}

\subsection{Characterization of the Subjects}

This study has a sample of 13 subjects, seven former gappers, five family members or close friends and one financial supportive person. The former gappers included five men and two women ages 1925. During their gap year, participants travelled in Europe, Asia, Africa and the United States of America. Four of them had their gap year experience funded by Fundação Lapa do Lopo. The other three self-funded their trip. Five gappers did volunteer work in places like schools or villages in Asia or Africa.

Five women and one man were interviewed as witnesses; three of the women were mothers and the other two were close friends. The final participant was the funding person responsible for a Portuguese private foundation.

The interviews were analysed following both the work objectives crossed with the main dimensions of interviews. In this way results were grouped in two sets. The first set was the identification and characterization of the changes that the gap year experience had on ex-gappers' beliefs and practices. A further classification of these changes is related with the dimensions of autonomy. The second set was the impact of such changes as they relate to citizenship and social commitment.

\subsection{Changes Related to the Gap Year Experience}

Most of the former gappers admitted to having changed their ambitions, their plans for the future and their personal way of looking at others.

In the case of $\mathrm{L}$, he felt that he had come back a more ambitious, dynamic and entrepreneurial person. $\mathrm{He}$ also felt more resilient and responsible after the journey. Finally, he confessed that the gap year increased his motivation and desire to prosper at university.

$\mathrm{B}$ and $\mathrm{H}$ made the gap year together and stated feeling more responsible, organised, independent and humble. They assured researchers that the gap year provided them with tools for life such as the ability of overcome problems and the motivation to study. B added that the experience made him grateful for having a chance to study and learn, something that in some countries most people desire but don't have the opportunity to do.

Unlike the previous participants, D didn't change his mind about his academic path. He claimed that the journey had affected him, however, arguing that the changes that occurred during the journey weren't tangible but internal-something that remains inside him. In this way, he sees himself in a different manner; he gained autonomy and responsibility; he felt more prepared to act under pressure and to solve problems in an easier way; and he became more respectful about different cultures and more willing to help others. He summarized his experience arguing that the changes it brought were valuable not only to the college but also for his personal curriculum.

Similarly M didn't change his plans for college, but he stated that the trip changed his mind-set for the future. After returning from the gap year he became involved in a number of extracurricular projects, revealing that he wanted to use the skills he developed in a broader way. These included communication skills, responsibility, organizational competences and an ability to face problems. In addition to this involvement and social commitment with several organizations, $M$ also felt more motivated to perform academic duties.

Former gapper $\mathbf{J}$ reported some similarities with the previous participants. She felt she had become more humble during the travel experience and more available to others. Furthermore, she stated that her leadership and team skills as well as her ability to overcome problems increased due to gap year. The experience also helped her to figure out what she wanted to do for the future, changing her former intentions concerning scholarship and increasing her academic motivation.

The last former gapper interviewed was $\mathrm{P}$, and she also changed her mind about the college programme in which she wanted to enrol. P also said that due to the gap year she sees the world differently, appreciating and giving more value to small things. Her experience also helped her to accept and respect the different cultural issues of some places, namely in Africa. Regarding personal skills development, she came back more autonomous, organised, independent, able to overcome problems and more capable of analysing risks. 
All of the witnesses (relatives or close friends of the former gappers) confirmed that these young people changed as a consequence of the travel experience. The gappers came back with clear ideas about their future, with a broader vision of others' realities and with an upgrade in their personal skills. So, in a general way, all the witnesses confirmed the changes that the former gappers mentioned during their interviews.

Finally, the funding person also stated that these young people came back different. He emphasized that what they saw, lived and learnt during the gap year enabled them to grow up faster and more deeply. He said that they came back with clearer ideas, were more motivated and more conscious, and had a greater sense of maturity. In his opinion these changes are due to the fact that they experienced diverse realities and had to move away from their comfort zone, which challenged and improved their skills.

The change categorizations related to autonomy are summarized in Table 1 Dimensions of autonomy.

Table1. Autonomy dimensions in changes occurred in former gappers

\begin{tabular}{|l|l|l|l|}
\hline \multicolumn{4}{|c|}{ Dimensions of autonomy } \\
\hline Self-efficacy & Control & Initiative & Motivation \\
\hline Entrepreneur (L; WM) & $\begin{array}{l}\text { Resilient (L; WM; WG; } \\
\text { WP) }\end{array}$ & Dynamics (L; WM) & Ambition (L) \\
\hline $\begin{array}{l}\text { Independence (L; B; } \\
\begin{array}{l}\text { M; G; P; FP; WH; } \\
\text { WL; WP) }\end{array}\end{array}$ & $\begin{array}{l}\text { Organization (H; D; G; P; } \\
\text { WH; WG; WP) }\end{array}$ & $\begin{array}{l}\text { Responsibility (L; B; H; } \\
\text { WL; WP) }\end{array}$ & $\begin{array}{l}\text { Motivation to prosper in } \\
\text { College (L; B; M; WM) }\end{array}$ \\
\hline $\begin{array}{l}\text { Capacity of } \\
\text { overcoming problems } \\
\text { (L; B; H; D; M; G; P; } \\
\text { FP; WB; WL; WG) }\end{array}$ & $\begin{array}{l}\text { Humility } \\
\text { (B; H; G; WB; WL; WG; }\end{array}$ & $\begin{array}{l}\text { Involvement in } \\
\text { extracurricular projects } \\
\text { W; D; M) }\end{array}$ & \\
\hline $\begin{array}{l}\text { Communications skills } \\
\text { (L; B; H; D; M; G; P; } \\
\text { WH; WG) }\end{array}$ & $\begin{array}{l}\text { Ability to act under } \\
\text { pressure (L; B; H; D; M; } \\
\text { FP) }\end{array}$ & & \\
\hline Leadership (G; D; M;) & Maturity (D; B; M; G) & & \\
\hline
\end{tabular}

\section{Acronyms:}

FP: Funding Person

WH: Witness of $\mathrm{H}$.

WB: Witness of B.

WL: Witness of L.

WM: Witness of M.

WG: Witness of G.

WP: Witness of P.

\subsection{Citizenship Main Issues}

During their travels, the gappers faced some constraints on their concept and practices of citizenship as they relate to different cultures. The most unanimous difference found in the gappers' interviews was about education, which also was the main dimension of their volunteer work. The schools were in remote locations, were isolated from the cities, and had many travelling hours separating the two points. The gappers also faced the poor conditions of the schools, with none of the supplies that are usual in Portuguese schools; some of them even lacked chairs or tables.

Concerning education, the ex-gappers referred that in such conditions, the teachers had a lack of training and had very little knowledge about the subjects they were supposed to be teaching. Still other difficulties were that, in some places, the teachers didn't receive a salary but lived on the money that the kids (students) could raise.

Without any prior training, gappers taught children. They oriented themselves as they advanced in the subjects. But the experience had a good impact on them, as they stated in the interviews, and made them highlight another cultural difference they faced - the huge respect these kids had for their teachers and the volunteers. The fact that the gappers indicated this respect from the children underlines a cultural difference between the country to which they travelled and Portugal. 
Another cultural shock was the paddling the teachers gave the students when they missed school, for instance. After the initial shock, the gappers realized it was a way to keep stable the hierarchy of the school, and neither the kids nor the teachers held any resentment about the situation. Thus, although the schools had worse conditions compared to Portugal, there was a greater dedication from the children to learn and to be good students.

The gappers had to face other cultural shocks concerning the daily habits and living conditions and the fact that the countries they travelled to do not have a social state.

Gappers reported episodes related to daily life conditions like having no running, clean or warm water, and even needing in some places to carry their own water to use. They also sometimes did not have electricity, and in some places they had to bathe in cauldrons of water heated at the fire pit, while in other places they had to use a mug to wash.

Food and eating were other different cultural experiences. They ate food typical for the area; sometimes it was very spicy and different from their normal diet and taste. They didn't use forks because no one used them. They sometimes slept on the floor or in a wood bed like the locals, and usually there were no bathrooms.

Among shocking travel experiences also was the feeling of being a target of many locals, as they were seen as tourists. They felt very much under the pressure of the street vendors, always negotiating everything from food to means of transport. One of the gappers said that he and his friends had to leave a house where they were couch-surfing to escape an attempted extortion. Another time they stayed in the city, also in a couch-surfing house, but had to take a bath using a mug and a small pot because the bathroom was so dirty that was impossible to use.

In two cases, ex-gappers referred to health facilities to say that the health systems were very different from what they were used to in Portugal. The hospitals were poor and dirty, the equipment wasn't sterilized and the drugs had no information about their components.

All of these cultural shocks helped the gappers to return more humbled and open to others and the difficult living conditions they face. Living actively with the locals during this period of time enabled the gappers to understand certain habits and traditions. For instance, the girl who travelled to Africa made contact with the phenomenon of female genital mutilation. She told us it first was a shock, but after she realized that it was lived by local young women as a desire and a transition ritual of growing in their culture. Therefore, although she did not agree with such a practice, she framed it into a larger cultural landscape.

\subsection{Changes in Social Commitment}

These changes had and still have an impact on the lives of these former gappers. First, in three cases, these changes affected the choice of higher education study. All of the gappers came back more motivated to study, which can contribute to prevention of failure and/or of dropping out and is an evidence of self-control and self-effectiveness. Therefore, the gap year was a booster and had a positive effect on the academic path of these young people.

The experience had an impact not only academically but also personally and even professionally because the gappers developed a set of skills that are useful and fundamental in several fields. The development of these soft skills-like communication, organization, team work ability, leadership and autonomy - were stressed in the interviews as the gappers had to solve problems without habitual help from their family.

In a more personal way, the former gappers returned with a strong willingness to create and take risks in life and also with a greater respect and recognition for the other. In general, they all came back extremely motivated to achieve their goals in life and to enjoy the most of it. The fact that most of them joined other social activities after the gap year experience emphasizes the idea of their increased citizenship and social commitment.

M, who did the journey alone, came back more eager to actively participate in society through involvement in various associations and organizations, taking part in numerous extracurricular projects. This is due to the fact that the '... journey gave me the competences for... grab a project, or an association, or another idea that I have and carry it forward...' (M). He also became aware of the impact he could have in society and more determined to commit to create and join causes that could have some social impact. 
'My mind-set changed a little [derived from the journey] as to what I will do beyond university. [...] so from the time I came back I had these defined goals... "I'm going to make this, doing this, being involved in this"... and that's what make a difference in my journey... being able to think... more than just the studies, what I see myself doing, where I see myself working... what is the impact that I want to have...' (M).

This commitment may be related with lessons $\mathrm{M}$ took from the journey. Among these are respect for otherness and an open mind and curiosity about other people's way of thinking and living. 'It's up to us to look at things and trying to understand people. Even if things doesn't make sense to us... learning to look without prejudice and curiosity are skills I will take everywhere in life' (M).

In the discourse of $\mathrm{G}$, another gapper who did her trip alone, we find a high sense of valuing people and comprehending different ways of living and thinking. During her journey she developed a sense of community, understanding and appreciation of others. She argued that this was due to the fact that she always had been dependent on people; she relied on strangers for housing, transportation and living experiences in the country.

'I felt more open to others... feeling like everybody has something to teach me... and then feeling a little more humble... I was always dependent of people, and people were always available to help me... [...] and this experience gave me other vision of the world, with other perspective of what I want... and other perspective about people...' (G).

Also with $\mathrm{P}$ we found respect and understanding toward other cultural practices and also a desire to be an active participant in those places. She learned to understand things that she thought were wrong because she saw them from the point of view of the locals.

'There were somethings that shocked me a little... but today I understand them better and already see them otherwise... one of them was that teachers beat the kids at school. As teachers did (in Portugal, 50 years ago) in the time of Salazar... give paddled hands... when pupils were missing school, when they lacked respect... they went to the staff room and got paddled... First time I saw it got me nervous... I wanted to interfere... but then I realize the hierarchy between teacher and student... the respect... they [the kids] didn't become traumatized because of it... so, eventually, I got accustomed to it. [...] other thing was the female genital mutilation... that for us [western civilization] it's something horrible... and there... they [the girls] want that... they want that to be respected by their husbands... they want that because their mothers had done it, their grandmothers had done it... Now I think that we should learn to respect and not only reject and criticize for being a different culture... we also have our own disgusting habits. [...] each country is how it is... and every culture is as it is... and since people are good' (P).

So she realized we are all different, each one of us having different habits, but also very much alike.

'The basic things that govern us are universal, whether is love, family and food, as dreams. What they want is to study, to have a job, being able to feed the family, make the family grow... our dreams may be a little more complex, but deep down it is that too...' (P).

This way of thinking reflected P's desire to be more aware of these different realities and to understand even more the different ways of living and thinking. So she expressed her desire to go on and work in places like Africa or Asia, not only with the purpose of helping, but also knowing more by direct contact.

The only gapper who showed more involvement and commitment to society after the journey was L. The impact the gap year had on him made him want to return to others what he had gained and to promote an equal opportunity for others to have a chance to do the journey like him. '(...) after knowing that I had a great opportunity, that somebody had opened my horizons, I decided I should return these feeling in a certain way to society' (L). 
The financier argued that these young people returned more socially aware and compromised than before. According to him this is a reflection of the experiences they had during the journey, knowing other cultures and being independent for the first time and having to solve their own problems.

In a general way all the witnesses interviewed felt that young people returned more humble and more willing to help others, and even to return, if possible, to society what they gained during the gap year. Therefore there was the unanimous opinion that they respected more other people and cultures and were determined to help friends or strangers, whether in college or in another country. P's witness went further and claimed that she had returned a citizen of the world and desired to give back to others, an idea that summarized all the opinions collected from the witnesses.

\section{CONCLuSions}

Gap year experience changes ex-gappers' beliefs and practices broadly related to autonomy. They evidence behaviors of greater self-efficacy, control, initiative and motivation. They return from the travelling experience more autonomous, a finding that is related with the findings of Jones (2004) in his report on gap year within the United Kingdom context. 'Greater independence and ability to take decisions, the development of interpersonal, leadership and communication skills and ability to managing money and problem solving' were the personal benefits reported by Jones (2004) that are possible to identify in present study.

These changes are closely related with conditions of traveling but also with motivations to travel. In such an interpretation it is possible to agree with O'Shea (2011) concerning the largely egoistic motivations of gappers as they 'intended to use the experience to obtain a variety of perceived benefits, often to develop skills, perspectives, and traits that they felt they lacked and had not developed in school or home community' (p. 568).

The ex-gappers' more autonomous behaviour is not only related with more independent personal actions and self-organization but also is related to clearer positions concerning their citizenship and social commitment. This result is more obvious among those who travelled alone and had stablished more extended and close relations with people they found during the travel.

Regarding citizenship issues, it is possible to acknowledge that ex-gappers enlarged their respect for cultural differences as a result of the gap year experience. They also were more aware of the importance of social justice. Freedom and democracy are values that are important to them but they discovered that they were not of equal importance to the people they contacted and related to during their travel.

\section{REFERENCES}

[1] Araújo, L \& Mouraz, A. 2015a. No intervalo: a experiência do Gap Year na transição entre o secundário e a Universidade. Revista de Estudios e Investigación en Psicología y Educación. Vol. Extr., 14, 14-22.

[2] Araújo, L \& Mouraz, A. 2015 b. Crossing the gap between high school and Higher Education: The gap year experience. In Carlinda Leite. Ana Mouraz \& Preciosa Fernandes (Orgs.) Curriculum Studies: Policies, Perspectives and Practices (p.286- 293). Porto: CIIE - Centro de Investigação e Intervenção Educativas. E-book. ISBN: 978-989-8471-21-5.

[3] Biesta, G. 2009. Good education in an age of measurement: On the need to reconnect with the question of purpose in education. Educational Assessment, Evaluation and Accountability, 21, 33-46.

[4] Bogdan, R. \& Biklen, S. 1994. Investigação qualitativa em educação. Porto: Porto Editora.

[5] Coetzee, M. \& Bester, S. 2009.The possible value of a Gap Year: A case study, South African Journal of Higher Education. 23 ( 3), pp. 608-623.

[6] Crawford, C. \& Cribb, J. 2012. Gap Year takers: uptake, trends and long term outcomes. London: Centre for Analysis of Youth Transitions (CAYT).

[7] Duarte, M. Leite, C. \& Mouraz, A. 2016. The effect of curricular activities on learner autonomy: the perspective of undergraduate mechanical engineering students. European Journal of Engineering Education.41(1), 91-104

[8] Heath, S. 2007 Widening the gap: pre-university Gap Years and the 'economy of experience', British Journal of Sociology of Education. 28 (1), 89-103 
[9] Johan, N. 2009. 'Gap Year travel: youth transition or youth transformation?', in R. Brooks (ed) Transitions from education to work: new perspectives from Europe and beyond (pp.136-149 ) . Basingstoke: Palgrave Macmillan.

[10] Jones, A. 2004. Review of Gap Year Provision, Research Report No 555, London: Department for Education and Skills.

[11] Kant, I. 1988. A paz perpétua e outros opúsculos. Lisboa: Ed. 70. (1. ed.1784).

[12] Martin, A.J. 2010.Should Students Have a Gap Year? Motivation and Performance Factors Relevant to Time Out After Completing School. Journal of Educational Psychology. 102. (3), 561-576.

[13] Mary, A. 2014. Re-evaluating the concept of adulthood and the framework of transition, Journal of Youth Studies, 17:3, 415-429.

[14] Mouraz, A. \& Sousa, A. 2015. An institucional approach to first-year adjustment: The "Projeto FEUP" casa study of a Portuguesa university. Journal of Hispanic Higher Education.i-first.

[15] Nico, M. 2014. Variability in the transitions to adulthood in Europe: a critical approach to destandardization of the life course, Journal of Youth Studies, 17(2), 166-182.

[16] O'Shea, J. 2011. Delaying the academy: A Gap Year education. Teaching in Higher Education $16,(5), 565-577$.

[17] Raymond, E. M., \& Hall, C. M. 2008. The development of cross-cultural (mis)understanding through volunteer tourism. Journal of Sustainable Tourism, 16, 530-543.

[18] Ribeiro, A. 2014. Why am i less than the others? A biographical study of first Generation students' vulnerability in portuguese higher Education. Social Work \& Society, 12 (2), 1-15.

[19] Simpson, K. 2004. Doing Development: The Gap Year, Volunteer-Tourists and a Popular Practice of Development. Journal of International Development, 16, 681-692.

[20] Sinnema C. \& Aitken, G. 2014. Emerging International Trends in Curriculum. In Priestley, M. $\&$ Biesta, G. (org.) Reinventing the curriculum. (pp.141- 163). London: Bloomsbury.

[21] Snee, H. 2010. Does travel broaden the mind? A critical review of learning through the Gap Year. LlinE, XV. (3), 159-168.

[22] Spenader, A. J. 2011 Language Learning and Acculturation: Lessons From High School and Gap-Year Exchange Students. Foreign Language Annals, 44, (2), 381-398. 